\title{
La Defensa de la Unidad del Lenguaje Común de Hispanoamérica
}

$\mathbf{H}$ ACE ya aproximadamente un siglo que el insigne escritor hispanoamericano don Andrés Bello expresaba su preocupación por la suerte de la lengua española en América: "Juzgo importante la conservación de la lengua de nuestros padres en su posible pureza, como un medio providencial de comunicación y un vínculo de confraternidad entre las varias naciones de origen español derramadas sobre los dos continentes." $\mathrm{Y}$ después de lamentarse de los vicios que desnaturalizaban entonces nuestra lengua, agregaba: "Pero el mayor de todos, y el que, si no se ataja, va a privarnos de las inapreciables ventajas de un lenguaje común, es la avenida de neologismos en la construcción, que inunda y enturbia mucha parte de lo que se escribe en América y alterando la estructura del idioma tiende a convertirlo en una multitud de dialectos irregulares, licenciosos, bárbaros; embriones de idiomas futuros, que durante una larga elaboración reproducirían en América lo que fué la Europa en el tenebroso período de la corrupción del latín."

He citado estas palabras del prólogo puesto por Andrés Bello a su excelente Gramática de la Lengua Castellana, porque son hoy la expresión exacta del peligro que amenaza a la lengua común de Hispanoamérica. Quizá los que la hablamos y escribimos como nativa, $y$ por ello no hallamos dificultad alguna para interpretar las variaciones, no concedemos toda la importancia que tienen a las diferentes maneras de expresarse empleadas en los distintos países de habla española. En esto, como en otras cosas, se nos llama desde fuera la atención. El profesor Kany, de la Universidad de California, ha publicađo un libro de 463 páginas que lleva por título: American 
Spanish Sintax. Aunque su objeto es poner de relieve las diferencias entre la lengua de España y la de Hispanoamérica, lo cierto es que, por las citas de escritores de este continente, se observa también una gran diversidad en los modos de expresión. Esto lo sabemos quienes hemos vivido algunos años en Hispanoamérica y seguimos paso a paso el movimiento literario hispanoamericano, pero causa bastante impresión ver reunidas y clasificadas en un grueso volumen tantas diferencias entre unos y otros países hermanos.

No sería razonable, sin embargo, exagerar la importancia de las variaciones entre la lengua hablada o escrita de las distintas naciones de Hispanoamérica, ni las que existen entre el idioma de ésta y el de España. Creo que el problema debe plantearse en sus verdaderos y justos términos, sin estimar irremediable el daño de posibles escisiones lingüísticas que destruyan la unidad idiomática hispanoamericana, pero sin desdeñar tampoco el peligro de que se produzcan.

Para la consideración objetiva del problema habremos de fijarnos primordialmente en un hecho muy significativo. Hace más de un siglo que la mayor parte de las naciones americanas de habla española - todas, excepto Cuba- se emanciparon del poder de la monarquia borbónica y viven independientemente. No ha existido entre ellas una relación muy estrecha, dificultada unas veces por sus luchas y siempre por la falta de vías de comunicación. Los contactos que han tenido con España fueron, en cierto modo, desiguales. En todo este largo período las naciones hispánicas han desarrollado su lengua con entera libertad, sin ningún concierto entre ellas y sin sombra alguna de autoridad que las unifique, pues hasta la puramente técnica y tradicional de la Academia Española ha ido en decadencia desde hace tres cuartos de siglo por el escaso acierto en la elección de sus miembros. Pues bien, no obstante la independencia politica y la total autonomía lingüística, bien sabido es que ninguna persona nacida e instruída en cualquier pais de lengua hispánica tiene la menor dificultad, no ya para entenderse en la conversación con los habitantes de las demás naciones donde se habla español, sino para ganarse la vida en actividades en que se ejercita la palabra oralmente - abogados, actores, profesores, vendedores, etc.o por escrito -novelistas, periodistas, empleados de escritorio, etcétera-. Las diferencias de pueblo a pueblo, todavía no muy numero- 
sas, son de pequeña importancia y se aprenden a las pocas semanas de cambiar de residencia. Afectan a algunos sustantivos, adjetivos y verbos, pero se conserva la unidad casi absolutamente respecto de las demás partes de la oración. Muchas de las variaciones observadas en la sintaxis son en realidad incorrecciones gramaticales.

El problema de las diferencias en el habla de los distintos paises hispanos no es, hoy por hoy, grave ni inminente. Son inevitables cuando hay una lengua común para varias naciones que se extienden, sobre todo, en un gran continente y viven bastante incomunicadas. En España, con ser la cuna del idioma y tener geográficamente muy poca extensión, existen, además de las otras tres lenguas peninsulares, localismos y formas provinciales de hablar dentro de la propia Castilla, es decir, modalidades dialectales, también numerosas en las demás regiones del país. No es extraño, pues, que en América, donde han actuado nuevas $\mathrm{y}$ específicas causas de variación -influencias indígenas y geográficas principalmente- las diferencias sean mayores.

Pero la presente situación puede considerarse en absoluto satisfactoria, pues las particularidades idiomáticas no ocasionan la menor dificultad para las relaciones personales ni para la intercomunicación cultural entre los paises de habla española -España e Hispanoamérica- que tienen tradicionalmente una común civilización. El ideal sería que no hubiera en las formas de expresión más diferencias que las absolutamente precisas -impuestas por la necesidad de dar nombre o verbo a nuevas cosas o acciones-, norma que reduciría mucho el número de estos localismos. Sin embargo, aun excediendo ahora los existentes de esa medida, no causan en realidad perjuicio alguno.

El problema se presenta, no obstante, mirando al porvenir. Es natural que las diferencias vayan en aumento por efecto de las mismas causas que las han producido, tal vez intensificadas por virtud de las nuevas circunstancias de la vida moderna. $\mathrm{Y}$ de este modo parece muy posible que dentro de cierto número de años la unidad lingüística de Hispanoamérica se rompa para dar origen a unas cuantas hijuelas dialectales, con enorme perjuicio de la cultura y de otros valores que hoy poseen dieciocho naciones independientes de este hemisferio, al aparecer los que Bello llama "embriones de idiomas futuros, que durante una larga elaboración reproducirian en 
América lo que fué la Europa en el tenebroso período de la corrupción del latin".

Frente a este peligro pueden adoptarse tres diferentes actitudes, que no son meramente hipotéticas, sino que se han mostrado más o menos francamente en la conducta de los representantes de significadas zonas del pensamiento hispanoamericano $y$ en manifestaciones de algunos escritores.

Cabe el criterio de defender a toda costa y decididamente la conservación del valioso tesoro cultural de la unidad idiomática de Hispanoamérica, que permitirá a sus habitantes - cuya cifra se acercará a los doscientos millones para fines de este siglo- ocupar un alto puesto en la civilización del continente y del mundo. La conservación y depuración de nuestra lengua común requerirá, sin duda, esfuerzos no pequeños por parte de los gobiernos, de los centros de enseñanza, de la prensa, de los maestros, de los escritores y de los hispanoamericanos en general, pero debe hacerse porque de la realización de este magnífico propósito depende, principalmente, la subsistencia de la personalidad y el acrecentamiento del prestigio de Hispanoaméricá.

Cabe, también, que las cosas sigan su curso espontáneo y que como las aguas sin cauce pierdan impulso y dirección. Pero las consecuencias de "esta abstención llevariañ a la pérdida del principal instrumento de culturà de los pueblos, que es la plena posesión de una lengua en la que muchos millones de hombres se den cuenta de las conquistas del pensamiento $\mathrm{y}$ de los avances de la ciencia. El enorme beneficio que proporcionan, por ejemplo, la lengua inglesa, la española o la francesa, consiste en que mediante ellas pueden escribirse libros para muchos millones de personas y leerse libros escritos por muchos millares de autores. Contribuir con la inacción a que, por no defender la unidad de la lengua hispanoamericana, se fraccione ésta en varios lenguajes vernáculos en los que, dentro de dos o tres generaciones, vivan aislados los pueblos hispánicos de América, equivaldria a privar a los hispanoamericanos del porvenir de la mejor herencia espiritual que puede transmitírseles.

Hay una tercera inclinación, de la que, por fortuna, participan sólo algunos escritores tocados de megalomanía o intoxicados por un pernicioso nacionalismo. Creen estos pocos literatos, de mentalidad lugareña, que debe fomentarse la formación de un lenguaje típico 
y propio de cada país como afirmación de su personalidad y signo de su potencia creadora. Grave error, que originaría enormes daños si se generalizare, hasta el punto de predominar en los paises hispanoamericanos. No es fácil crear un nuevo idioma nacional distinto de nuestra lengua materna. $\mathrm{El}$ coro de cretinos que alienta las extravagancias chistosas de cualquier cómico populachero puede dar origen a una jerigonza más o menos inteligible. El desmandamiento lingüistico de determinados núcleos sociales puede elaborar una jerga como el "lunfardo" argentino. La espontaneidad comarcal de una región incomunicada puede dar lugar a un islote dialectal. Pero no creo que sea deseable la creación de jerigonzas, "lunfardos" o dialectos que sirvan para andar por casa solamente. Así no se sirve a la cultura y al progreso. $Y$ únicamente el genio singular de un pueblo privilegiado - por algo predominó Castilla y se impuso el castellano en Iberia-, en determinadas circunstancias históricas, es capaz de crear una lengua como ésta, en que escribieron sus obras Cervantes, Lope de Vega, Quevedo, Pérez Galdós y Valle Inclán, en España; Ruiz de Alarcón, Sor Juana Inés de la Cruz, Sarmiento, Montalvo, Dario, Rodó y Martí, en América; por no citar más que algunos de los muchos insignes escritores que enaltecieron la literatura hispánica.

Tenemos el deber de conservar y defender la unidad y la pureza de la lengua común de Hispanoamérica y de España, a toda costa, si queremos seguir siendo una constelación magnífica en el firmamento de la cultura mundial. Esto no quiere decir que el idioma de los hispanoamericanos haya de someterse a la disciplina arcaica de los "don Hermógenes" gramáticos, ni tampoco a los dictados de la Academia Española, a la cual podrían decir sus "correspondientes" de Hispanoamérica, como los procuradores de Cortes medioevales al rey: "Nos que cada una de nosotras valemos tanto como vos $y$ que juntas valemos más que vos..." Tampoco significa mi opinión que el habla del mundo hispánico deje de evolucionar sin adaptarse a las necesidades de expresión de los nuevos tiempos. Es suficiente no desnaturalizar, no corromper y no escindir esta maravillosa lengua que tan bien les sirve ahora a los habitantes de Hispanoamérica y de España para entenderse mutuamente, y procurar que siga desenvolviéndose con arreglo a su genio singular y a su naturaleza. 
¿Cómo se ha de llevar a cabo esta gran labor de defensa de la lengua y de su preciada unidad continental? A mi parecer, el plan de defensa y su realización habrán de ser continentales también, pues necesitan verdaderamente el concurso de todos. De los gobiernos, que deberían prestar el apoyo de su autoridad a las medidas que se propongan; de las Universidades, como altos centros de cultura, orientadoras del movimiento; de las Academias de la Lengua, por tratarse uno de sus propósitos fundamentales; de los maestros de primera enseñanza, llamados a desarrollar el amor a la lengua nativa y el cuidado de su pureza; de la prensa, que tanto puede hacer con sus campañas y dando ejemplo de corrección en su lenguaje; de los escritores, que deberán abandonar los localismos buscando en lo posible formas de amplio vuelo y pulcritud gramatical; de los locutores de radio, que se hallan en contacto tan frecuente con auditorios de extensión continental; de todos los hispanoamericanos, en suma, puesto que a todos afecta el problema y se necesita su colaboración para resolverlo:

¿Y la iniciativa? La iniciativa podria tomarla una organización de carácter continental, consagrada al estudio del movimiento literario en Hispanoamérica, y por ello me permito someterla a la consideración del Instituto Internacional de Literatura Iberoamericana:

- Jerónimo MaLlo, University of Iowa. 